
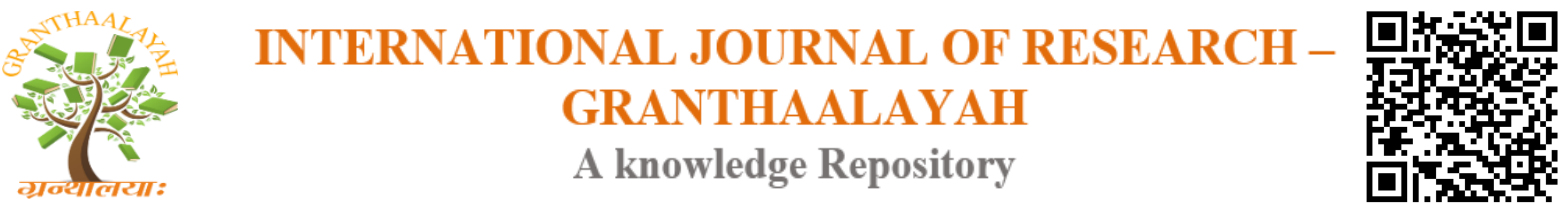

Social

\title{
TRANSFORMATIONAL REHABILITATION: COMMUNITY-BASED INTERVENTION TO END THE DRUG MENACE
}

\author{
Generoso N. Mazo ${ }^{* 1}$ \\ ${ }^{*}$ Ph.D., Leyte Normal University, Tacloban City, Philippines
}

\begin{abstract}
Eradication of the drug menace is the centerpiece program of the Duterte administration. The President claims there are more than 4 million drug users in the country. The police, used the "tok tok-hangyo" or "knock and appeal" approach, to encourage drug users, pushers and others involved to surrender and stop their illegal activities. The nationwide response was overwhelming as 1,176,523, pushers and users submitted voluntarily to authorities. In Tanauan, Leyte, 396 persons, and still increasing, surrendered. Without a national blueprint on how to deal with this problem, Local Governments are left to craft their own programs to help their constituents. The Transformational Rehabilitation Plan Community-Based Approach to Drug Prevention and Moral Recovery Program, a 3-Phases modular approach was implemented with a general objective to enable the participant to understand the process of healing and recovery from their old lifestyles and embrace the new life for the future.
\end{abstract}

Keywords: Drug Prevention; Moral Recovery; Rehabilitation Modules; Community Involvement and Healing and Recovery.

Cite This Article: Generoso N. Mazo. (2017). "TRANSFORMATIONAL REHABILITATION: COMMUNITY-BASED INTERVENTION TO END THE DRUG MENACE." International Journal of Research - Granthaalayah, 5(12), 183-190.

\section{Introduction}

The issue on illegal drugs had been the battle cry that catapulted Davao City Mayor Duterte to the Presidency. The eradication of this menace has been the centerpiece program of his administration. In several of his speeches the President claimed that there are more than 4 million drug users in the country.

Aside from the Philippine Drug Enforcement Agency (PDEA), the agency mandated by law to implement the Dangerous Drugs Law, President Duterte as the Commander-in-Chief directed the Criminal Investigation and Detection Group (CIDG) of the Philippine National Police (PNP) to lead his war on drugs. The police responded with an innovative tactic called "toktok-hangyo" (tokhang) or "knock and appeal" approach. The main purpose of this method was to encourage 
drug users, pushers and others involved in the proliferation of the illegal drug trade to voluntarily surrender and stop their illegal activities.

The nationwide response to the constant appeal cum threat of President Duterte and the consistent "tokhang" operations in all levels of the Philippine society was truly unexpected. The reaction was overwhelming as $1,176,523$, pushers and users submitted voluntarily to authorities according to police records. Tanauan, Leyte had its share of voluntary surrenderees.

As a town that had been, worst hit by Super Typhoon Haiyan/Yolanda and just on its way to recovery, the menace of illegal drugs was a big threat to its dream of rebuilding Tanauan to be a delightful community. The Local Government Unit (LGU) spearheaded by the local chief executive had to take proactive actions to curb this problem in its own backyard.

\section{Theoretical Framework}

The theories of transformational leadership, theoretical principles of the transformational model of rehabilitation and the community-based rehabilitation model were the frameworks of this study.

Connelly, Marks, Mumford, \& Zaccaro (2000) as quoted by Potter (2004) identified the qualities of transformational leadership as inspirational motivation, intellectual stimulation, individualized consideration, management by exception, and contingency reward. Potter (2004) also quoted (Jones and Moses, 1999) that transformational leadership is centered on the capacity to move resources for greater productivity. Bower (1997) said it requires adaptability and flexibility. It is about leadership with values and meaning, and a purpose that transcends short-term goals and focuses on higher order needs. In this study, the characteristics of a transformational leader were observed in the decisions and actions taken by the local chief executive in spearheading the creation of the community-based approach to rehabilitate the drug surrenderees.

Forster (2007) offered 7 theoretical principles of the transformational model of rehabilitation, specifically: 1) The goal of rehabilitation is the transformation in personal identity; 2) the transformational process is achieved through increased awareness of and acceptance of self; 3 ) awareness and acceptance of self is made possible through the experiences of relationships which are committed, co-operative, and compassionate; 4) transformation leads to maturity; 5) maturity permits a person to act with agency and authenticity; 6) agency and authenticity militates against burnout, and; 7) maturity permits individuals to contribute to relationships which are committed, co-operative and compassionate. These principles are found embedded in the activities of the 3 phases transformational rehabilitation plan.

Forster also proposed the Community-based Rehabilitation The community-based rehabilitation (CBR) model is similar to the transformational model of rehabilitation. Both of these models view the relationship as one of collaboration between client and professional. Both are interested in building the capacities of clients. Despite their similarities, these models differ in their definition of the problem. Within CBR, the problem is one of social processes and structures and therefore, takes on a political nature. Within the transformational model, the problem is one of personal identity and the lack of appreciation of one's own unique identity. The difference in 
problem definition means these two models also differ in the desired outcomes associated with the work which is being done. CBR is a political strategy which is focused on the development of local community structures in under-developed countries. Although CBR is more recently informing community development strategies in developed countries, its primary focus is with local community processes and structures. Transformational rehabilitation is concerned with personal identity and the development of relationships which promote maturity in individuals living with and without disabilities. While the transformational outcome of maturity as agency and authenticity is expected to have an impact on interpersonal relations, these impacts are felt at the relational and not the political or social level. Therefore, transformational rehabilitation does not have the same political or social impact that is found within a CBR approach. These characteristics were also found entrenched in the specific objectives of the different activities in the module.

The Dangerous Drugs Board's (DDB) 2015 Nationwide Survey on the Nature and Extent of Drug Abuse in the Philippines survey on the drug use situation in the Philippines show there were 1.8 million current drug users in the Philippines or $1.8 \%$ of the total population of 100.98 million. The ages of the drug users ranged from 10 to 69 years old.

According to DDB Chairperson Benjamin Reyes, the government's anti-illegal drug campaign should also focus on prevention to "curb the problem." "As much as possible, we are trying to prevent the 4.8 million to not try using illegal drugs again." The key message is to not use and do not try illegal drugs because retention rate is high. Retention rate refers to the percentage of drug users that will continually use a specific illegal drug. The 2015 drug situation survey results showed that drug retention rate is currently at $28 \%$ for shabu and $24.7 \%$ for marijuana.

Data from the Philippine Drug Enforcement Agency (PDEA) stated that 11,132 out of 42,036 barangays in the country were affected by the drug menace as of December 2015.

Hechanova (2017), Head of the Psychological Association of the Philippines (PAP) Task Force on Drug Recovery, claimed some $90 \%$ of reported drug users are "low- or mild-risk" users. They need not be admitted to rehabilitation centers. They include people who are casual users who are not dependent on drugs but who may have difficulties because of temptation, of their work, or their environment. The PAP initiated the Katatagan Kontra Droga sa Komunidad in partnership with schools and local government units (LGUs). Their main aim was to teach community facilitators and volunteers from partner communities how to facilitate drug rehabilitation. There is a need for an evidence-based intervention as there is a lot of ignorance on what to do for the drug users. This is apparent in the superficial programs like "Zumba," rolled-out by some LGUs which simply divert the surrenderees attention from drug use. The PAP designed 12 modules based on cognitive behavioral therapy, aimed at equipping surrenderers with skills to recover from drug use. Based on their needs analysis, drug use was sometimes prompted by conflicts. Almost $90 \%$ of drug users have lived in communities of violence. Some $60 \%$ grew up with emotional neglect or abuse even. A lot of pain characterize their pasts and drugs was a means to escape that. PAP also developed 3 modules for affected families with surrenderers in order for them to understand the possible reasons for drug use and how the family can identify new ways of relating with the user. Many of the offenders or users can be treated outside. They don't really need rehabilitation as in-patients. 
In August 2016, the City Government of Valenzuela launched its comprehensive anti-drug support program dubbed as "VC Cares Plus" which include, among other integrated strategies, an LGU-funded assessment, community based and center-based rehabilitation, and reintegration program for drug dependents. The City sent a total of 199 drug dependents to a locally funded six month long therapy program at the Central Luzon Drug Rehabilitation Center in Magalang, Pampanga, making the City the first local government unit in the country to sponsor drug dependent for rehabilitation. The cost of rehabilitation of each Valenzuelano patient was PhP 6,500 per month or Php 39,000.00 for the entire treatment period. Alongside the rehabilitation sponsorship, families of bread-winner rehab patients were taken cared of by the local government and were given food subsidies to make them worry-free while they are away. Upon their return to their respective communities after the rehabilitation, they had to report to the community based rehabilitation units which were set up in each barangay of the city. They were also be provided with livelihood or job placement support through the Public Employment Service Office (PESO) to enable their full transformation as renewed and productive constituents of the city. Those who wanted to return to school were made to avail of the education programs of the city, such as, the Alternative Learning System (ALS) or scholarship program.

\section{Objectives}

This study aimed to know the design and implementation method of the transformational rehabilitation plan community-based approach to drug prevention and moral recovery program in the Municipality of Tanauan, Leyte. The persons and entities involved, their roles and perceptions on the program.

\section{Methodology}

Using the descriptive case study method (Baxter and Jack, 2008), data were gathered through, 1. Personal interviews with the local chief executive, volunteers, and other key implementers, and; 2. Observations of the actual conduct of the modular approach moral recovery program from the start to their graduation.

\section{Results and Discussion}

Tanauan is a $2^{\text {nd }}$ class municipality in the Province of Leyte. It is politically subdivided into 54 barangays. It has 53,310 population in 12,386 households.

Data from the Police Intelligence reflected that 24 out of 54 or $44 \%$ of the barangays were affected by the menace of illegal drugs influencing $1.2 \%$ of the population.

As of December 2016 the local police had recorded 396 drug related surrenderees or reformers or $0.74 \%$ of the population. They were pre-dominantly males and majority were unemployed.

In September 2016, the local chief executive gathered representatives from the different sectors and volunteers to map out plans to tackle the influx of drug surrenderees in response to the Oplan "tok-hang" of the PNP. He emphasized the ill-effects of illegal drugs to the community can be equated to the damage of super typhoon Haiyan/Yolanda. "This is similar to the Haiyan/Yolanda 
experience where countries all over the world came together to help us rebuild from the ruins brought by the super typhoon. Now it is our time to rally our entire community, we must come together to address this menace." In this case, the whole community includes the Local Government Unit, Police, Barangay Officials and Leaders, Church Leaders, religious and lay workers, schools, family members, other stakeholders such as the Department of Interior and Local Government (DILG), Philippine Drug Enforcement Agency (PDEA), Department of Social Welfare and Development (DSWD), Philippine National Police (PNP), and the Archdiocese of Palo. Everyone came together to meet this menace head on and accepted the challenge of rehabilitating the victims of drugs while respecting their human rights. The main consideration was the value of life and importance of second chances.

The group drew-up a Transformational Rehabilitation Plan that was a Community-Based Approach to Drug Prevention, Intervention and Moral Recovery Program. The main concept was the program would run for a 2-month period and would meet the whole day of every Sunday. In charge of the actual rehabilitation activities were the Agustinian Sisters, SALAG group, KAAGAPAY team, MSWD team, and the Family Life Apostolate group. The LGU provided the venue and other logistics for the food, transportation and other materials for the activities.

\section{Program Summary}

The Transformational Rehabilitation Plan Community-Based Approach and Moral Recovery Program, a 3-Phases modular approach was implemented with the general objective to enable the participant to understand the process of healing and recovery from their old lifestyles and embrace the new life for the future.

\section{Phase I - Self Knowledge and Personality Development}

\section{Objectives}

1) Be able to understand the importance of self and belongingness in the family and in the community and society.

2) Be able to encourage the participants to paint what was happening and realize the value and sanctity of life.

\section{Main Activities}

1) My Identity and Sense of Belongingness

2) Art Therapy

3) Personality Development

4) Group Counseling

5) Spiritual Nourishment

\section{Other Activities}

- Levelling off

- Hangkop Pamilya (Embracing the Family)

- One Day Advent Recollection

- General Orientation

- Physical Fitness Program 
- Regular Accounting and Monitoring

- Referral

- Medical Treatment

\section{Phase II - Family Healing and Reconciliation}

\section{Objectives}

1) Be able to provide a venue for dialogue for their family and foster reconciliation to one another;

2) Be able to provide a venue for the dialogue of life and with one another;

3) Be able to provide a venue for bonding and deepen their understanding on the value of family life.

\section{Main Activities}

1) Healing Family Relationships

2) Healing Family Tree

3) Family Counseling

4) Family Integration

\section{Other Activities}

- Home Visitation

- Area Follow-up

- Family Visitation

Phase III - Community Integration

\section{Objectives}

1) Be able to foster the drug awareness campaign and the effects of illegal drugs in their life;

2) Be able to participate on the advocacy on anti-illegal drug campaign and to foster drug awareness in their respective communities.

\section{Main activities}

1) Community Renewal Encounter

2) Social Integration

3) Illegal Drug Summit

4) Graduation/Culmination Rites

\section{Other Activities}

- Community Service

- Sports Festival

- Random Drug Testing was a requirement before a surrenderee was allowed to graduate from the program.

The local chief executive had also tapped the resources and programs of other government agencies for the, leadership training, skills and livelihood training program for the graduates. 
Voluntary contributions from concerned individuals and corporate entities through their corporate social responsibilities were also extended as assistance to the graduates of the program.

\section{Conclusions}

The following conclusions are derived:

1) Based on the police estimates, there are still persons involved in the illegal drug activities who have not surrendered voluntarily.

2) The Transformational Rehabilitation Plan Community-Based Approach and Moral Recovery Program differed with the modules made by the Psychological Association of the Philippines because the transformational rehabilitation plan was focused on the rehabilitation of the surrenderee while the other modules focused on teaching community facilitators and volunteers how to facilitate drug rehabilitation.

3) The program was effective based on the feedback from the surrenderees and their families because it really addressed the inner core of their problems. The holistic approach and gradual realization from the self, to the family and to the community made them truly commit to mend their ways. These fits under the theoretical principles of the transformational model of rehabilitation and Community-based Rehabilitation model offered by Forster.

4) There is the need for follow-up after the 2 months modular class to prevent the back slide to their prior ways of life, however, there is still a lack of specific plan on how to continue the monitoring of graduates for the next 2 to 3 years.

5) The act of volunteering for the transformational rehabilitation program shows the eagerness of the surrenderees to renew their lives. This only reflects that they belong to the "low- or mild-risk" users. They need not be admitted to rehabilitation centers. This coincides with the observations of the Psychological Association of the Philippines.

6) The program has already graduated 37 surrenderees last March 7. The solemn activity was attended by their families and friends and this made the graduates feel important as it was graced by the Regional Directors of the DILG, DSWD, PDEA, PNP, and the town Mayor. The main presider was the Archbishop of the Diocese of Palo. The second batch will graduate by the end of this month of April.

7) The gaps in the implementation specifically on the monitoring of the graduates for a duration of 2-3 years creates an opportunity for the academe to join in this rehabilitation efforts as part of its extension services.

\section{Acknowledgement}

I would like to thank our University President Dr. Jude A. Duarte, for his consistent support to our research endeavors. To Mayor Pel Tecson and wife Penny. To my mother and in-house editor Dr. Leatriz N. Mazo. To my late father Dr. Jose V. Mazo. My wife and my inspiration, Rafaelita C. Mazo, for her unwavering love and understanding. Above all, to the Almighty God for His Divine Guidance and Providence 


\section{References}

[1] Forster, D.M. (2007). Jean Vanier and the Transformational Model of Rehabilitation: Principles of Care for Concerned Professionals. Unpublished Thesis School of Rehabilitation Therapy, Doctor of Philosophy Queen's University Kingston, Ontario, Canada. October.

[2] Hechanova, R., (2017) Head of the Psychological Association of the Philippines (PAP) Task Force on Drug Recovery

[3] http://news.pia.gov.ph/article/view/231476784879/valenzuela-city-funds-rehabilitation-of-199drug-dependents retrieved April 19, 2017.

[4] www,pdea.gov.ph

[5] www.dilg.gov.ph

[6] www.pnp.gov.ph

*Corresponding author.

E-mail address: roskymazo@yahoo.com 